\title{
Effect of positive expiratory pressure breathing in patients with cystic fibrosis
}

\author{
C P van der Schans, Th W van der Mark, G de Vries, D A Piers, H Beekhuis, \\ J E Dankert-Roelse, D S Postma, G H Koëter
}

\begin{abstract}
The effect of positive expiratory pressure breathing, alone and in combination with coughing, was investigated in eight patients with cystic fibrosis. Functional residual capacity and total lung capacity was measured with a body plethysmograph before, during, and immediately after breathing with expiratory pressure of 5 and $15 \mathrm{~cm} \mathrm{H}_{2} \mathrm{O}$, and after a coughing period. The positive expiratory pressure breathing was carried out five times for two minutes with a two minute interval between each period. Mucus transport was measured in a peripheral lung region and over the whole lung by a radioactive aerosol tracer technique. Clearance measurements were carried out continuously during positive expiratory pressure breathing and during a control period. Two minutes' breathing with an expiratory pressure of 5 and 15 cm $\mathrm{H}_{2} \mathrm{O}$ caused an increase in mean (SEM) functional residual capacity from $2.6(0.1)$ to $3.6(0.3)$ and $4.4(0.5) 1$ and an increase in total lung capacity from $5 \cdot 1$ $(0.2)$ to $5.9(0.3)$ and $6.9(0.4) 1$. Lung volumes were higher during breathing with an expiratory pressure of $15 \mathrm{~cm}$ $\mathrm{H}_{2} \mathrm{O}$ than with $5 \mathrm{~cm} \mathrm{H}_{2} \mathrm{O}$; both returned to baseline values immediately after positive expiratory pressure breathing. Spontaneous mucus clearance and mucus clearance by coughing were not influenced by positive expiratory pressure breathing at either expiratory pressure. Thus in patients with cystic fibrosis positive expiratory pressure breathing increases lung volumes in relation to the expiratory pressure imposed; these changes in lung volume did not, however, lead to an improvement of mucus transport.
\end{abstract}

In patients with cystic fibrosis retention of mucus and consequent respiratory tract infections are one of the main causes of deterioration in lung function. ${ }^{1}$ Physiotherapy, including forced expirations with an open glottis and coughing, is frequently applied to increase mucus transport and thereby reduce mucus retention. These measures contribute to the preservation of lung function, ${ }^{2}$ and may reduce the number of exacerbations of respiratory tract infection.

Positive expiratory pressure breathing has been used in patients with chronic airflow obstruction, ${ }^{3-6}$ in an attempt to improve ventilation and reduce mucus retention, and has been introduced more recently for patients with cystic fibrosis. ${ }^{7} \mathrm{~A}$ face mask is usually used with an inspiratory tube, containing a one way valve, and a variable expiratory resistance, resulting in a positive expiratory pressure throughout expiration of 5 or $15 \mathrm{~cm} \mathrm{H}_{2} \mathrm{O}$. Application of positive expiratory pressure breathing to patients with cystic fibrosis is based on the hypothesis that mucus in peripheral small airways will be mobilised by coughing or a forced expiration if alveolar pressure is increased. Two mechanisms might lead to an increased volume of air behind mucus plugs during positive expiratory pressure breathing and thus to an increase in pressure in closed alveoli: an increase in intrabronchial pressure, which increases the pressure gradient between open and closed alveoli, and an increase in functional residual capacity, which reduces the resistance in collateral and small airways. ${ }^{89}$

The results of earlier studies on the effect of positive expiratory pressure breathing in patients with cystic fibrosis are contradictory. Some studies suggest that physiotherapy, including positive expiratory pressure breathing, leads to more mucus expectoration than conventional physiotherapy; ${ }^{7}$ but other studies have failed to confirm this. ${ }^{10-12}$ Some authors have shown that physiotherapy that includes positive expiratory pressure breathing improves lung function in patients with cystic fibrosis, ${ }^{71314}$ and arterial blood gas values improved in one study of patients with various disorders ${ }^{15}$ but not in others. ${ }^{10-1216}$ There are no data on the effect of positive expiratory pressure breathing on lung function and mucus clearance in these patients.

If positive expiratory pressure breathing increases alveolar pressure behind mucus plugs by increasing the amount of gas in closed parts of the lungs, it should lead to an increase of thoracic gas volunie (TGV) that lasts some time after positive expiratory pressure breathing has ceased. Mucus plugs may subsequently be mobilised more effectively by forced expirations and coughing, after which TGV should return to its baseline value.

The purpose of our study was to determine whether positive expiratory pressure breathing increases thoracic gas volume, and whether any increase in lung volume is associated with increased mucus clearance rates during positive expiratory pressure breathing. We examined two expiratory pressures followed by a coughing period. 
Methods

PATIENTS

We studied eight patients with cystic fibrosis, aged 13-21 (mean (SD) 16 (3)) years. All were in a clinically stable phase of their disease, as assessed by lung function tests and a short questionnaire on the days of measurement. All had regular daily expectoration of mucus, but the amounts were too small for reliable measurement. The mean (SD) forced expiratory volume in one second $\left(\mathrm{FEV}_{1}\right)$ was $70 \%$ (24\%) predicted, functional residual capacity (FRC) $94 \%(17 \%)$ predicted, and volume of trapped gas $0.6(0.2) 1$. For patients younger than 18 years the predicted values of Zapletal $e t$ $a l^{17}$ were used and for patients of 18 or more the predicted values of Tammeling. ${ }^{18}$ All patients used antibiotics periodically for respiratory tract infections. The patients continued their regular medication without change during the study. Routine physiotherapy was not given on the days of measurement. All patients, or their parents, gave their written informed consent. The study was approved by the medical ethics committee of the University Hospital.

\section{LUNG FUNCTION MEASUREMENTS}

$\mathrm{FEV}_{1}$, total lung capacity (TLC), and slow inspiratory vital capacity (VC) were measured with a water sealed spirometer; residual volume (RV) and FRC were assessed with a helium dilution technique. Thoracic gas volume was measured in duplicate at functional residual capacity (TGVFRC) and at total lung capacity (TGVTLC) with a body plethysmograph (Gould), mean values being used for analysis. Volume of trapped gas was calculated by subtracting FRC from TGVFRC. During a 20 minute positive expiratory pressure breathing session, carbon dioxide production and oxygen uptake were calculated from mixed expiratory gas concentration and minute volume, using automatic equipment (Jäger Eos Sprint).

\section{MUCUS CLEARANCE MEASUREMENTS}

Mucus clearance was measured as described previously. ${ }^{19}{ }^{20}$ Briefly, a heterodisperse aerosol was produced by an intermittent positive pressure respirator (Bennet AP-5), with 35-50 $\mathrm{MBq}$ technetium-99m labelled tin colloid (Amersham). Before inhalation of the aerosol peak expiratory flow (PEF) was measured to ensure that the degree of airflow obstruction was similar on the different days of measurement, as airflow obstruction influences the aerosol deposition pattern. ${ }^{21} 22$ After 40 inhalations $10-15 \%$ of the tracer was deposited in the airways. A gamma camera was situated behind the patient's thorax and connected to a computer for continuous acquisition of one minute frames over 45 minutes.

The initial deposition pattern was quantified by expressing the amount of radioactive tracer in the peripheral region of the lung as a percentage of whole lung deposition. The decreases in radioactivity in the peripheral region and in the whole lung region over 30 and 45 minutes were analysed.

\section{STUDY DESIGN}

Three physiotherapy protocols $(\mathrm{A}, \mathrm{B}, \mathrm{C})$ for improving mucus transport were evaluated, on different days in randomised order. Measurements were always made at the same time of the day, after 11.00 hours. Protocol A was used as a control measurement. During protocols B and C positive expiratory pressure breathing was performed with a relatively flow independent positive expiratory pressure (PEP) mask (Vital Signs), ${ }^{23}$ with expiratory pressures of 5 and 15 $\mathrm{cm} \mathrm{H}_{2} \mathrm{O}$. On the measurement days the protocol was carried out twice, first with measurement of mucus clearance and the second time with lung function measurements. The interval between the end of the mucus clearance measurement and the beginning of the lung function tests was about 45 minutes.

The protocols were as follows:

Protocol $A$ (1) Mucus clearance was measured continuously for 45 minutes, with the patient supine. In the period from 30 to 35 minutes the patient was asked to cough every 30 seconds as productively as possible. (2) Spirometric values and lung volumes were determined before and immediately after the coughing period.

Protocol B (1) Mucus clearance measurements were made as before but in the period from 10 to 30 minutes the patient breathed intermittently through a PEP mask with an expiratory pressure of $5 \mathrm{~cm} \mathrm{H}_{2} \mathrm{O}$, breathing through the PEP mask for two minutes, followed by two minutes of undisturbed breathing; this was repeated five times. The patient was then asked to cough as productively as possible every 30 seconds for a further five minutes. (2) Spirometric values and lung volumes were determined before and after the PEP mask breathing. The patient, sitting in the body plethysmograph, breathed through the PEP mask (connected to the mouthpiece of the body plethysmograph) for two minutes. During and immediately after this period of PEP mask breathing TGVTLC and TGVFRC were measured. The patient then breathed again through the PEP mask for two minutes, followed by two minutes without the mask; this was repeated four times. TGVFRC and TGVTLC were measured in each period between the PEP mask breathing. Finally the patient was asked to cough every 30 seconds, as productively as possible, for five minutes.

Protocol $C$ This was identical to protocol B except that the expiratory pressure of the PEP mask was $15 \mathrm{~cm} \mathrm{H}_{2} \mathrm{O}$. In five patients, carbon dioxide production and oxygen uptake were measured continuously during a third 20 minute positive expiratory pressure breathing session, which was performed after protocol C. The patient, seated, breathed through a PEP mask with an expiratory pressure of $15 \mathrm{~cm} \mathrm{H}_{2} \mathrm{O}$ for two minutes, followed by two minutes of undisturbed breathing; this was repeated five times.

\section{STATISTICAL ANALYSIS}

Differences in radioactive tracer clearance after 30 and 45 minutes and differences in lung 
Thoracic gas volume at functional residual capacity ( $)$ and at total lung capacity ( $)$ during protocol $A$ (baseline), protocol $B$ (during and after $\left.\mathrm{PEP} 5 \mathrm{~cm} \mathrm{H}_{2} \mathrm{O}\right)$, and protocol $C$ (during and after $P E P 15 \mathrm{~cm}$ $\left.\mathrm{H}_{2} \mathrm{O}\right)$. PEP $5 \mathrm{~cm}-t w o$ minutes of positive expiratory pressure (PEP) breathing with an expiratory pressure of $5 \mathrm{~cm}$ $\mathrm{H}_{2} \mathrm{O} ; \mathrm{PEP} 15 \mathrm{~cm}$ - $\mathrm{Pwo}$ minutes of PEP breathing with an expiratory pressure of $15 \mathrm{~cm} \mathrm{H}_{2} \mathrm{O}$.

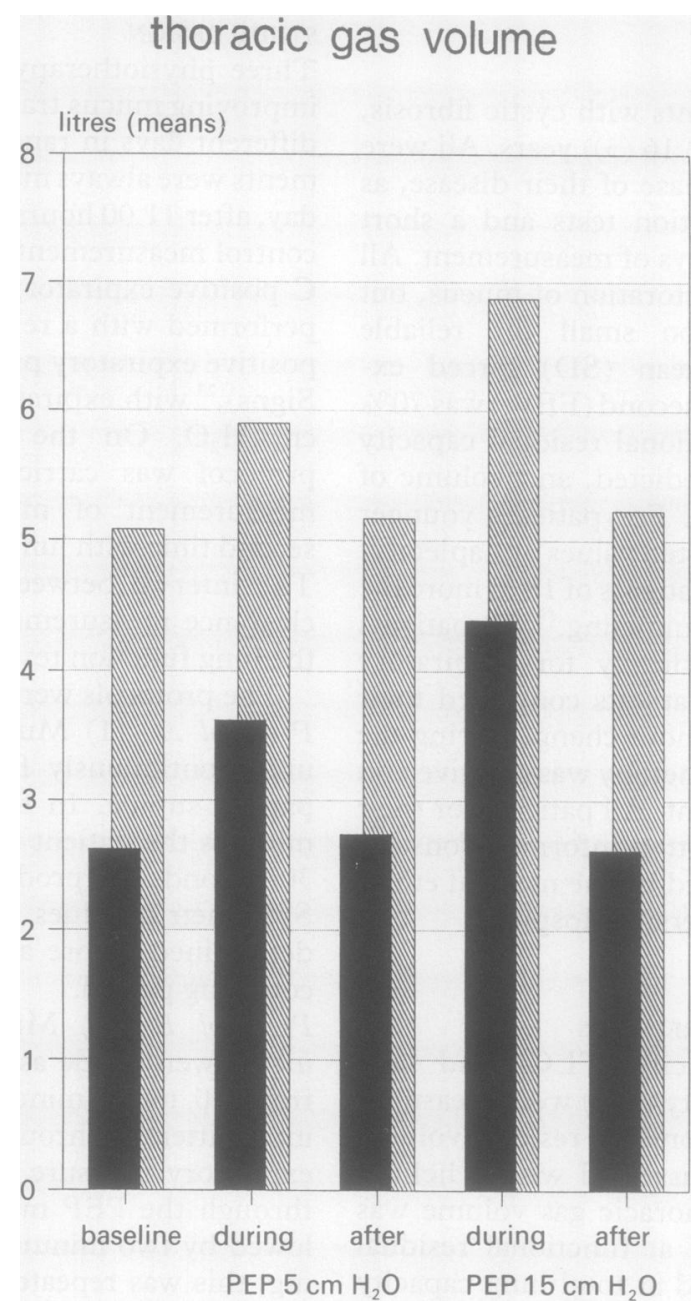

function values were compared by means of Student's $t$ test for paired samples. A significant difference was defined as $p<0.05$. All calculations were performed with the Statistical Package for the Social Sciences. ${ }^{24}$

\section{Results}

PULMONARY FUNCTION

After protocol A TGVTLC increased slightly but significantly $(\mathrm{p}<0.01)$, from a mean (SEM) $5 \cdot 0(0 \cdot 2) 1$ to $5 \cdot 1(0 \cdot 2)$ l. Other lung function values did not change significantly after the coughing period.

During positive expiratory pressure breath- ing, with an expiratory pressure of $5 \mathrm{~cm} \mathrm{H}_{2} \mathrm{O}$ (protocol B) and an expiratory pressure of 15 cm $\mathrm{H}_{2} \mathrm{O}$ (protocol C), mean (SEM) TGVFRC increased from $2.6(0.1)$ to $3.6(0.3)$ and 4.4 $(0.5) 1$ respectively; mean TGVTLC increased from $5 \cdot 1(0 \cdot 2)$ to $5 \cdot 9(0.3)$ and $6.9(0.4) 1$ (figure). The differences from baseline values were significant $(p<0.02)$. TGVFRC and TGVTLC were significantly $(p<0.05)$ higher during positive expiratory pressure breathing with an expiratory pressure of $15 \mathrm{~cm} \mathrm{H}_{2} \mathrm{O}$ than with an expiratory pressure of $5 \mathrm{~cm} \mathrm{H} \mathrm{H}_{2} \mathrm{O}$. TGVFRC and TGVTLC returned to the baseline rapidly after discontinuation of positive expiratory pressure breathing with protocols $B$ and C. TGVFRC and TGVTLC did not change significantly after the coughing period in protocol B or C. Other pulmonary function values did not change significantly during protocols $\mathrm{B}$ and $\mathrm{C}$.

During a positive expiratory pressure breathing session of 20 minutes, oxygen uptake and carbon dioxide production remained stable in the five patients studied, who showed no signs of fatigue (table). The respiratory quotient (RQ) was higher than in healthy subjects.

\section{MUCUS CLEARANCE}

Mean (SEM) PEF, measured before inhalation of the radioactive tracer, did not differ significantly between the three protocols (A 375 (28), B 363 (25), and C 367 (5) 1/min. The initial deposition pattern of the radioactive tracer did not differ significantly for protocols A, B, and C, the mean (SD) \% peripheral deposition being 76 (3), 75 (3), and 75 (5).

Neither peripheral mucus clearance nor whole lung mucus rclearance at 30 minutes differed significantly after positive expiratory pressure breathing in protocols $B$ and $C$ from clearance during the same period without treatment (protocol A), mean (SEM) \% peripheral clearance being for A 6 (1), B 8 (1), and C 5 (2), and mean (SEM) \% whole lung clearance A 8 (2), B 10 (2), C 6 (2). There were also no significant differences in mucus clearance at 45 minutes between the three protocols after inclusion of the five minutes of coughing, mean (SEM) \% peripheral clearance being for A 9 (2), B 10 (2), and C 11 (4), and mean (SEM) \% whole lung clearance A 11 (3), B 13 (2), and C 13 (3).

\section{Discussion}

The effectiveness of conventional pulmonary physiotherapy designed to improve mucus transport is probably confined to the large airways in patients with cystic fibrosis. ${ }^{25}$ In these patients, however, insufficient mucus transport and tenacious respiratory tract secretions lead to small peripheral airways obstruction, which may cause atelectases. Attempts are therefore being made to develop a physiotherapy technique that mobilises mucus in small peripheral airways. In patients with postoperative pulmonary complications continuous positive airway pressure, positive end expiratory pressure, and positive expiratory pressure breathing are effective measures to reopen collapsed parts of the lungs. ${ }^{26-28}$

*Two minutes of undisturbed breathing. †Two minutes of PEP breathing with an expiratory pressure of $15 \mathrm{~cm} \mathrm{H}_{2} \mathrm{O}$. RQ-respiratory quotient. 
Obstructed areas are thought to reopen as a result of increased collateral ventilation. ${ }^{8}$ Falk et al suggested that this might occur in patients with cystic fibrosis, mucus possibly being mobilised from peripheral small airways.

All patients in our study tolerated positive expiratory pressure breathing well. This was confirmed by our observation in five patients that the respiratory quotient, though increased at rest, remained stable during a 20 minute positive expiratory pressure breathing session with an expiratory pressure of $15 \mathrm{~cm} \mathrm{H}_{2} \mathrm{O}$. Some patients used the PEP mask as part of their respiratory physiotherapy at home and they reported, spontaneously or on being questioned, subjective improvement after positive expiratory pressure breathing, especially with the expiratory pressure of $15 \mathrm{~cm} \mathrm{H}_{2} \mathrm{O}$. This subjective improvement supports our impression that compliance seems to be better for positive expiratory pressure breathing than for other respiratory physiotherapy measures. Surprisingly, none of the patients claimed a specific improvement in expectoration after positive expiratory pressure breathing, either at home or during our study.

Each protocol in our study was carried out twice with an interval of 45 minutes. Lung function was always measured during the second session. As lung function has been shown to return to baseline within 15 minutes of physiotherapy, ${ }^{14}$ including positive expiratory pressure breathing, we think that it is valid to compare the two protocol sessions. The results of our study show that positive expiratory pressure breathing in patients with cystic fibrosis increases TGVFRC, even when the expiratory pressure is lower than that usually recommended by physicians and physiotherapists, and also lower than that used in other investigations. ${ }^{5710-16}$ The increase in TGVFRC and TGVTLC was related to the expiratory pressure. The increase of TGVTLC during positive expiratory pressure breathing is possibly due to the opening up of collateral pathways or small airways in obstructed parts of the lungs as a result of an increased end expiratory volume. ${ }^{29}$ Our investigations show that increasing lung volume for short periods does not lead to improvement in spontaneous mucus transport or mucus transport induced by coughing. The latter may be because TGV returned to baseline values immediately after positive expiratory pressure breathing. If obstructed parts of the lungs are opened by positive expiratory pressure breathing they appear to collapse again immediately afterwards, probably as a result of anatomical changes in the lungs. Coughing is unlikely therefore to be influenced by positive expiratory pressure breathing.

We observed no significant change in the volume of trapped gas after the three protocols. This contrasts with the findings of Groth $e t a l,{ }^{14}$ who found a reduction after positive expiratory pressure breathing combined with coughing and forced expiration with an open glottis. The reduction found by Groth et al may be due to other components of their physiotherapy regimen.
The increase in lung volumes during positive expiratory pressure breathing in our study may reduce unequal ventilation and lead to an improvement in arterial blood gas tensions, as was found by Herala et al. ${ }^{15}$ It is uncertain whether these short term improvements in arterial blood gases are clinically important in patients with cystic fibrosis but they may explain the subjective improvement claimed by our patients.

Another type of positive expiratory pressure breathing has been described by Oberwaldner et $a l^{\beta 0}$ and may be more effective, though the expiratory pressures of more than $60 \mathrm{~cm} \mathrm{H}_{2} \mathrm{O}$ used by these authors may cause complications. In this technique the patient is asked to expire forcefully through a PEP mask with an expiratory resistance; the patient is therefore "coughing" at a time when some parts of the lungs should be reopened by increased collateral ventilation, thus mobilising mucus plugs in small airways.

Our study in patients with cystic fibrosis has shown that positive expiratory pressure breathing for two minutes on five occasions temporarily increases lung volume, but this does not improve mucus transport.

1 Fick RB, Stillwell PC. Controversies in the management of pulmonary disease due to cystic fibrosis. Chest 1989;95:1319-27.

2 Desmond KJ, Schwenk WF, Thomas E, Beaudry PH, Coates AL. Immediate and long-term effects of chest physiotherapy in patients with cystic fibrosis. $J$ Pediatr 1983;103:538-42.

3 Thoman RL, Stoker GL, Ross JC. The efficacy of pursedlips breathing in patients with chronic airflow obstructive pulmonary disease. Am Rev Respir Dis 1966;93:100-6.

4 Mueller RE, Petty TL, Filley GF. Ventilation and arterial blood gas changes induced by pursed lips breathing. $J$ Appl Physiol 1970;28:784-9.

5 Hengstum van M, Festen J, Beurskens $C$, et al. The effect of positive expiratory pressure versus forced expiration technique on tracheobronchial clearance in chronic bronchitis. Scand J Gastroenterol 1988;23(suppl 143):114-8.

6 Barach AL. Physiologic advantages of grunting, groaning, and pursed-lip breathing: adaptive symptoms related to the development of continuous positive pressure breathing. Bull NY Acad Med 1973;49:666-73.

7 Falk M, Kelstrup M, Andersen JB, et al. Improving the ketchup bottle method with positive expiratory pressure, PEP. A controlled study in patients with cystic fibrosis. PEP. A controlled study in patien
Eur J Respir Dis 1984;65:57-66.

8 Menkes HA, Traystman RJ. State of the art. Collateral ventilation. Am Rev Respir Dis 1977;116:287-309.

9 Peters RM. Pulmonary physiologic studies of the perioperative period. Chest 1979;76:576-84.

10 Tyrell JC, Hiller EJ, Martin J. Face mask physiotherapy in cystic fibrosis. Arch Dis Child 1986;61:598-611.

11 van Asperen PP, Jackson L, Hennessy P, Brown J. Comparison of positive expiratory pressure (PEP) mask with postural drainage in patients with cystic fibrosis. Aust Paediatr J 1987;23:283-4.

12 Hofmeyer JL, Webber BA, Hodson ME. Evaluation of positive expiratory pressure as an adjunct to chest positive expiratory pressure as an adjunct to chest
physiotherapy in the treatment of cystic fibrosis. Thorax 1986;41:951-4.

13 Tonnesen $\mathrm{P}$, Stovring S. Positive expiratory pressure (PEP) as lung physiotherapy in cystic fibrosis: a pilot study. Eur Respir Dis 1984;65:419-22.

14 Groth S, Stafanger G, Dirksen H, Andersen JB, Falk M, Kelstrup M. Positive expiratory pressure (PEP-mask) physiotherapy improves ventilation and reduces volum of trapped gas in cystic fibrosis. Bull Eur Physiopatho Respir 1985;21:339-43.

15 Herala M, Gislason T. Chest Physiotherapy. Evaluation by transcutaneous blood gas monitoring. Chest 1988;93: 800-2.

16 Kaminska TM, Pearson SB. A comparison of postural drainage and positive expiratory pressure in the domiciliary management of patients with
chial sepsis, Physiotherapy 1988;74:251-4.

17 Zapletal A, Paul T, Samanek M. Normalni hodnoty statickych plinich objenu a ventilace u deti a mladistvych. $C s$ Pediatr 1976;31:532-9.

18 Tammeling GJ. Standard values for lung volume and ventilatory capacity of sanatorium patients [selected paper]. Amsterdam: Royal Netherlands Tuberculosis
Association, 1961. 
19 Schans van der CP, Piers DA, Postma DS. Effect of manual percussion on tracheobronchial clearance in patients with percussion on tracheobronchial clearance in patients with
chronic airflow obstruction and excessive tracheobronchial secretion. Thorax 1986;41:448-52.

20 Schans van der CP, Piers DA, Beekhuis H, Koëter GH, Mark van der ThW, Postma DS. Effect of forced expirations on mucus clearance in patients with chronic airflow obstruction: effect of lung recoil pressure. Thorax obstruction: effec

21 Dolovich MB, Sanchis J, Rossman C, Newhouse MT. Aerosol penetrance: a sensitive index of peripheral airways obstruction. J Apply Physiol 1976;40:468-71.

22 Garrard CS, Gerrity TR, Schreiner JF, Yeates DB. The characaterisation of radioaerosol deposition in the healthy lung by histogram distribution analyis. Chest 1981;80(suppl 6):840-2.

23 Banner MJ, Lampotang S, Boysen PG, Kirby RR, Smith RA. Resistance characteristics of expiratory pressure valves [abstract]. Anesthesiology 1986;65:A80.
24 Nie NH. Statistical package for the social sciences. 2nd ed. New York: McGraw Hill, 1975.

25 Weller PH, Bush E, Preece MA, Matthew DJ. Short-term effects of chest physiotherapy on pulmonary function in children with cystic fibrosis. Respiration 1980;40:53-6.

26 Andersen JB, Qvist J, Kann T. Recruiting collapsed lung through collateral channels with positive end-expiratory pressure. Scand J Respir Dis 1979;60:260-6.

27 Andersen JB, Olesen KP, Jansen E, Ovist J. Periodic Andersen JB, Olesen KP, Jansen E, Qvist J. Periodic continuous positive airway pressure, CPAP, by mask in

28 Ricksten SE, Bengtsson A, Soderberg C, Thorden M, Kvist $\mathrm{H}$. Effects of periodic positive airway pressure by mask on postoperative pulmonary function. Chest 1986;89:774-81.

29 Delaunois L. Anatomy and physiology of collateral respiratory pathways. Eur Respir J 1989;2:893-904.

30 Oberwaldner B, Evans JC, Zach MS. Forced expirations against a variable resistance: a new chest physiotherapy method in cystic fibrosis. Pediatr Pulmonol 1986;2:358-67. 